ten. The bent S6 model (Fig. 2) raises just about as many questions as it answers. Why, for example, is $\mathrm{S} 6$ bent in $\mathrm{K}_{\mathrm{v}}$ channels? Might this smaller open pore in $\mathrm{K}_{\mathrm{v}}$ channels serve to decrease the conductance of the channel beyond what is set at the selectivity filter, as Webster et al. ${ }^{2}$ suggest? Might the PVP adaptation serve an important role in the unusually tight coupling ${ }^{24}$ that occurs between the voltage sensors and the $S 6$ gate in $\mathrm{K}_{\mathrm{v}}$ channels? Clearly there is still much to learn and an X-ray structure of a $\mathrm{K}_{\mathrm{v}}$ channel with a PVP motif would be a big step forward. For now, the message seems to be that one size, or model, may not fit all.
1. Hille, B. Ion Channels of Excitable Membranes, xviii, 814 (Sinauer, Sunderland, Masssachusetts, USA, 2001).

2. Webster, S.M., Del Camino, D., Dekker, J.P. \& Yellen, G. Nature 428, 864-868 (2004).

3. Jiang, Y. et al. Nature 417, 523-526 (2002)

4. Armstrong, C.M. J. Gen. Physiol. 54, 553-575 (1969).

5. Armstrong, C.M. J. Gen. Physiol. 58, 413-437 (1971).

6. Armstrong, C.M. Q. Rev. Biophys. 7, 179-210 (1974)

7. Papazian, D.M., Schwarz, T.L., Tempel, B.L., Jan, Y.N. \& Jan, L.Y. Science 237, 749-753 (1987).

8. Timpe, L.C. et al. Nature 331, 143-145 (1988).

9. Kamb, A., Tseng-Crank, J. \& Tanouye, M.A. Neuron 1 421-430 (1988)

10. Holmgren, M., Smith, P.L. \& Yellen, G. J. Gen. Physiol. 109, 527-535 (1997).

11. Liu, Y., Holmgren, M., Jurman, M.E. \& Yellen, G. Neuron 19, 175-184 (1997).

12. del Camino, D. \& Yellen, G. Neuron 32, 649-656 (2001).

13. Holmgren, M., Shin, K.S. \& Yellen, G. Neuron 21 617-621 (1998).
14. Doyle, D.A. et al. Science 280, 69-77 (1998).

15. Zhou, M., Morais-Cabral, J.H., Mann, S. \& MacKinnon, R. Nature 411, 657-661 (2001).

16. Perozo, E., Cortes, D.M. \& Cuello, L.G. Science 285 73-78 (1999)

17. MacArthur, M.W. \& Thornton, J.M. J. Mol. Biol. 218, 397-412 (1991).

18. del Camino, D., Holmgren, M., Liu, Y. \& Yellen, G. Nature 403, 321-325 (2000).

19. Jiang, Y. et al. Nature 417, 515-522 (2002)

20. Zagotta, W.N., Hoshi, T. \& Aldrich, R.W. Science 250, 568-571 (1990).

21. Patlak, J.B. J. Gen. Physiol. 113, 385-388 (1999).

22. Smith-Maxwell, C.J., Ledwell, J.L. \& Aldrich, R.W. J. Gen. Physiol. 111, 421-439 (1998).

23. Hackos, D.H., Chang, T.H. \& Swartz, K.J. J. Gen. Physiol. 119, 521-532 (2002).

24. Islas, L.D. \& Sigworth, F.J. J. Gen. Physiol. 114, 723-741 (1999).

\title{
And the oskar goes to...
}

What specifies that a cell will become an antenna and not a leg? For fruit flies, cell fate is determined early in the cytoplasm of the egg. Here, maternal mRNAs and proteins are localized to different regions of the egg chamber creating gradients of macromolecules throughout the cell. The redistribution of these molecules during egg development and fertilization as well as the pattern of cell cleavage is important for determining which cell acquires which fate.

For proper abdomen and germ cell development in the future embryo, oskar mRNA must be localized at the posterior end of the Drosophila egg chamber. If the mRNA is not in the correct place, the embryo is sterile and has an incorrectly formed abdomen, which can be lethal. Previous work suggested that targeting to the posterior end of the egg was dependent on the $3^{\prime}$ untranslated region ( $3^{\prime} U T R$ ) of the RNA because oskar transcripts lacking the $3^{\prime}$ UTR failed to localize. Furthermore, the oskar 3'UTR was shown to be sufficient for posterior targeting. Now, Hachet and Ephrussi (Nature 428, 959-963, 2004) challenge the sufficiency of the 3'UTR for posterior targeting and show that splicing of the oskar mRNA is also essential for mRNA localization.

Hachet and Ephrussi generated transgenic flies expressing wildtype (oskWT) and intronless oskar (osk $\Delta i$ ) genes. They examined the egg chambers from these flies and located oskar mRNA using fluorescent in situ hybridization (red). The egg, where oskar mRNA will localize, is located on the right half of the oval egg chamber surrounded by a string of small cells (nuclei stained using DAPI, blue) and flanked on the left side by nurse cells (large blue nuclei). Hachet and Ephrussi show that during early egg development, the three introns (i1,i2 and i3) in oskar are dispensable for both nuclear export and the early phase of oskar

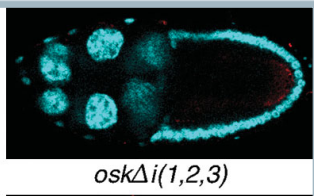

mRNA transport. However, as egg development proceeds, the distribution of oskar mRNA changes. In older oskWT egg chambers, the mRNA is found in a discrete position at the posterior end of the egg cytoplasm. In contrast, the mRNA is diffuse and not localized in flies lacking all three introns (osk $\Delta i$ 1,2,3). These results show that the introns are important for localization of oskar mRNA at the posterior of the egg.

Another unexpected finding from these studies was a role for $i 1$ in mRNA targeting but not for i2 or i3. The mRNA localization of osk $\Delta i(2,3)$ resembled that of wild type, whereas that of $o s k \Delta \mathrm{i}(1,2)$ and osk $\Delta i(1)$ is diffuse throughout the cytoplasm. All mRNAs were correctly spliced. Hachet and Ephrussi further demonstrate that splicing of the first intron, rather than a specific requirement for the sequence of the $i 1$, is essential for localization. When they replaced the sequence of $i 1$ with that of $i 3$ (osk(i3 in i1)) the distribution of oskar mRNA resembled that of oskWT. These data show that splicing at the first exon-exon junction of oskar mRNA and localization are mechanistically coupled.

The nuclear shuttling proteins Y14 and Mago nashi are also essential for oskar mRNA localization. These proteins are core components of the exon junction complex (EJC), which forms $\sim 20$ nucleotides upstream of the exon-exon junction. Although Hachet and Ephrussi did not analyze the composition of the EJC at the three different splice sites, they suggest that there is something fundamentally different about placing the EJC at the first exon-exon junction. The authors propose this EJC may play a pivotal role in mediating interactions between factors bound at the $5^{\prime}$ cap, the $3^{\prime} U T R$ and within the coding region of the oskar mRNA. In so doing, the EJC at the first splice site acts as a landmark for specifying an oskar mRNA localization complex.
Evelyn Jabri 